\title{
Surface modification of bacterial cellulose by nitrogen-containing plasma for improved interaction with cells
}

\author{
Renata A.N. Pertile ${ }^{\mathrm{a}, 1}$, Fábia K. Andrade ${ }^{\mathrm{a}, 1}$, Clodomiro Alves Jr. ${ }^{\mathrm{b}}$, Miguel Gama ${ }^{\mathrm{a}, *}$ \\ a Institute for Biotechnology and Bioengineering, Universidade do Minho (UM), Portugal \\ b Departamento de Física, Universidade Federal do Rio Grande do Norte (UFRN), Brazil
}

\section{A R T I C L E I N F O}

\section{Article history:}

Received 12 April 2010

Received in revised form 19 May 2010

Accepted 20 May 2010

Available online 27 May 2010

\section{Keywords:}

Bacterial cellulose

Nitrogen plasma treatment

$\mathrm{X}$-ray photoelectron spectroscopy

Cell adhesion

\begin{abstract}
A B S T R A C T
Bacterial cellulose (BC) membranes were modified with nitrogen plasma in order to enhance cell affinity. The surface properties of the untreated and plasma modified $\mathrm{BC}(\mathrm{BCP})$ were analyzed through contact angle measurements, X-ray photoelectron spectroscopy (XPS) and scanning electron microscopy (SEM). The effect of the plasma treatment on the adhesion of microvascular (HMEC-1), neuroblast (N1E-115) and fibroblast (3T3) cell lines was analyzed.

The nitrogen plasma treatment did not increase the wettability of the material, but increased the porosity and surface chemistry, as noticed by the presence of nitrogen. XPS analysis revealed the stability of the modified material along time and autoclave sterilization. The cell adhesion and proliferation of HMEC- 1 and N1E- 115 cells was significantly improved in the BCP, in contrast with the 3T3 cells, revealing a cell-specific effect. This work highlights the potential of plasma treatment for the modification of the BC surface properties, enhancing its potential for biomedical applications.
\end{abstract}

(c) 2010 Elsevier Ltd. All rights reserved.

\section{Introduction}

The surface characteristics play a vital role in the in vivo performance of biomaterials. The fate of implants is determined by the interactions - to a large extent cell-specific (Chu, Chen, Wang, \& Huang, 2002) - between the biomaterial and tissues. Polymeric materials do not always possess the specific bioactivity required to promote suitable interaction with cells, thus methods to enhance biocompatibility are required (Ma, Mao, \& Gao, 2007; Wang, Robertson, Spillman, \& Claus, 2004).

The surface properties of a scaffold, such as wettability, topography, chemistry, surface charge, the presence of hydrophobic and hydrophilic domains, density and conformation of functional groups, all play a crucial role in the cell-material interaction (Vesel, Junkar, Cvelbar, Kovac, \& Mozetic, 2008). The control of cell adhesion on the polymer substrate, and therefore the ability to guide proliferation, migration and differentiation, is highly desirable and a central issue in the development of scaffolds for tissue engineering (Lucchesi, Ferreira, Duek, Santos, \& Joazeiro, 2008).

\footnotetext{
* Corresponding author at: IBB-Institute for Biotechnology and Bioengineering, Centre of Biological Engineering, Universidade do Minho, Campus de Gualtar, 4710057 Braga, Portugal. Tel.: +351253 604400; fax: +351253678986.

E-mail address: fmgama@deb.uminho.pt (M. Gama).

1 Both these authors contributed equally to this work.
}

Surface properties may be altered by plasma treatment techniques. The modulation of the effects obtained is possible through control of operational parameters, including the gas used, reaction conditions (power, pressure and exposure time) and the reactor geometry (Wang, Lu, Zheng, \& Chen, 2006). Plasma technique is a convenient method to modify the surface properties of polymeric materials, keeping intact their bulk properties. Furthermore, it is an easy way to introduce the desired groups or chains onto the surface of materials with complex shape; being conducted in vacuum, the treatment is pervasive, which is an advantage in the case of scaffolds with interpenetrating porous structures often used for tissue engineering purposes (Yang, Bei, \& Wang, 2002).

Bacterial cellulose (BC) is a glucose linear polymer secreted by Gluconacetobacter xylinus in the form of nanofibers network, with appealing properties for tissue engineering, including high crystallinity, wettability, high tensile strength, moldability in situ and simple production (Svensson, Harrah, Panilaitis, Kaplan, \& Gatenholm, 2004). Although chemically identical to plant cellulose, $\mathrm{BC}$ is obtained free of other polymers and its macromolecular properties and structure are different (Vandamme, De Baets, Vanbaelen, Joris, \& De Wulf, 1998). Beyond these characteristics, the BC is biocompatible, which makes it ideal for the construction of biomedical devices (Helenius et al., 2006).

In this work, we aimed at modifying BC surfaces with plasma, in order to enhance its cell affinity. Cell adhesion and viability of different cell lineages were evaluated on BC surfaces before and after modification with nitrogen-containing plasma. The effect of plasma 
treatment, reported in this work for the first time with BC, was accessed through contact angle measurements, scanning electron microscopy (SEM) and X-ray photoelectron spectra (XPS).

\section{Material and methods}

\subsection{Bacterial cellulose production}

The BC membranes were produced by growing the G. xylinus purchased from the American Type Culture Collection (ATCC 53582 ) in Hestrin-Schramm medium, pH 5.0. The medium was inoculated and added to polystyrene Petri dishes ( $20 \mathrm{ml}$ per plate), for 4 days at $30^{\circ} \mathrm{C}$, in static culture. The membranes were purified with $2 \%$ sodium dodecyl sulfate (SDS) for $12 \mathrm{~h}$ at $60^{\circ} \mathrm{C}$, washed with distilled water until complete removal of SDS and immersed in a $4 \% \mathrm{NaOH}$ solution - gently shaken - for $90 \mathrm{~min}$ at $60^{\circ} \mathrm{C}$. After neutralization, the pellicles were autoclaved in distilled water and lyophilized.

\subsection{Cell culture}

Human Microvascular Endothelial Cells (HMEC-1) were cultured in RPMI 1640 medium (Invitrogen Life Technologies, UK), supplemented with 10\% FBS (Invitrogen Life Technologies, UK), 1\% penicillin/streptomycin (Sigma), $1.176 \mathrm{~g} / \mathrm{l}$ of sodium bicarbonate, $4.76 \mathrm{~g} / \mathrm{l}$ of Hepes, $1 \mathrm{ml} / \mathrm{l}$ of EGF and $1 \mathrm{mg} / \mathrm{l}$ of hydrocortisone $>98 \%$ (Sigma). 3T3 mouse embryo fibroblasts were cultured in Dulbecco's Modified Eagle Medium (DMEM; Sigma) supplemented with 10\% CBS (Invitrogen Life Technologies, UK), 1\% penicillin/streptomycin (Sigma). N1E-115 (rat neuroblasts) was cultured in DMEM (Sigma) supplemented with $10 \%$ fetal bovine serum (FBS; Gibco), $1 \%$ penicillin/streptomycin (Sigma). All cultures were maintained at $37^{\circ} \mathrm{C}$, in atmosphere of $5 \% \mathrm{CO}_{2}$ and $95 \%$ humidified air.

\subsection{BC surface modification by plasma treatment}

The lyophilized bacterial cellulose sheets were treated in a plasma reactor, fed with $\mathrm{N}_{2}$ (100\%). The plasma reactor used consists of a reaction chamber, a vacuum system, a system of power and data acquisition. In addition to two electrodes and an adjusting ring, the plasma chamber also included a glass cylinder $400 \mathrm{~mm}$ in length and $320 \mathrm{~mm}$ in diameter, generating a total volume of $0.32 \mathrm{~m}^{3}$. The ends of the tube are sealed by two stainless steel flanges. The connection of bottom flange held vacuum, pressure sensors and thermocouples. The power supply has an output continuously adjustable up to $1500 \mathrm{~V} \mathrm{DC}$ and current of $2 \mathrm{~A}$. The samples were fixed on the inside camera, using an adjustment ring, and placed between the two electrodes, at a distance of $4 \mathrm{~cm}$ from the cathode, as described previously (Costa, Feitor, Alves, Freire, \& de Bezerra, 2006). This distance was necessary to avoid thermal alterations on the surface during processing, once the cathode reached temperatures above $150^{\circ} \mathrm{C}$ during previous experiments. All treatments were performed under the same conditions: time (30 min); voltage (425 V), current $(0.20 \mathrm{~A}), \mathrm{N}_{2}$ flow (10 sccm), pressure ( 4 mbar). The cathode temperature was measured and controlled in the control panel.

\subsection{Determination of contact angles - wettability}

Water contact angles were measured using a face contact angle meter (OCA 20, Dataphysics, Germany). The contact angle of the untreated and treated bacterial cellulose surfaces was measured by the sessile drop method (Kwok \& Neumann, 1999), in which a $2 \mu \mathrm{l}$ droplet of ultra pure water (Milli Q) was placed on a horizontal $\mathrm{BC}$ surface and observed with a face contact angle meter. The angle formed by the tangent of the droplet with the surface was measured by image analysis.

\subsection{Scanning electron microscopy}

The BC samples were sputter-coated with gold and examined by scanning electron microscopy (SEM). The analyses were performed on a scanning electron microscope (Nova NanoSEM 200, The Netherlands) using an accelerating voltage of $5 \mathrm{kV}$.

\subsection{Analysis of X-ray photoelectron spectra (XPS)}

The XPS analysis was performed using an ESCALAB 200A, VG Scientific (UK) with PISCES software for data acquisition and analysis. For analysis, an achromatic $\mathrm{Al}(\mathrm{K} \alpha) \mathrm{X}$-ray source operating at $15 \mathrm{kV}(300 \mathrm{~W})$ was used, and the spectrometer, calibrated with reference to $\mathrm{Ag} 3 \mathrm{~d} 5 / 2(368.27 \mathrm{eV})$, was operated in CAE mode with $20 \mathrm{eV}$ pass energy. Data acquisition was performed at a pressure below $1 . \mathrm{E}-6 \mathrm{~Pa}$. Survey scan spectra were obtained at a pass energy of $50 \mathrm{eV}$, while for $\mathrm{C} 1 \mathrm{~s}, \mathrm{O} 1 \mathrm{~s}$ and $\mathrm{N} 1 \mathrm{~s}$ individual highresolution spectra were taken at a pass energy of 20 and a $0.1 \mathrm{eV}$ energy step. Spectra analysis was performed using peak fitting with Gaussian-Lorentzian peak shape and Shirley type background subtraction (or linear, taking in account the data). The binding energy $(\mathrm{eV})$ scales were referenced to the hydrocarbon component $(\mathrm{C}-\mathrm{C})$ in the C $1 \mathrm{~s}$ spectra at $285 \mathrm{eV}$.

Ageing of the plasma-treated samples was also observed by XPS analysis. In this case, the characterization was carried at different time intervals after plasma treatment; the samples were stored at room temperature.

\subsection{Cell adhesion and proliferation assay}

The mitochondrial activity of the cultured cells was determined using a colorimetric assay, which is related to cell viability. The MTS [3-(4,5-dimethylthiazol-2-yl)-5-(3-carboxymethoxyphenyl)2-(4-sulfophenyl)-2H-tetrazolium] assay was performed as follows: the bacterial cellulose sheets were cut into circular discs ( $15 \mathrm{~mm}$ diameter), sterilized by autoclaving and placed in 24-well tissue culture polystyrene plates; the $\mathrm{BC}$ sheets were kept at the bottom of the plate using homemade Teflon hollow cylinders, designed as to fit the wells of the polystyrene plate. Afterwards, $500 \mu \mathrm{l}$ of cell solution in culture medium was added to the wells $\left(6 \times 10^{4}\right.$ cells/well). Two hours after the addition of cells, the wells were washed with PBS and complete medium was added. Then, the MTS method was applied to quantify viable cells adsorbed on the $\mathrm{BC}$ membrane. The experimental time periods analyzed were 2 , 24 and $48 \mathrm{~h}$. The cell adhesion experiments were run in two independent assays, each one performed in triplicate. The plates were incubated for $2 \mathrm{~h}$ with MTS reagent, and then $100 \mu \mathrm{l}$ of each well were transferred to a new plate and read on a Micro Elisa reader (Biotech Synergy HT), with a wavelength of $490 \mathrm{~nm}$.

\subsection{Statistical analysis}

Experimental data were analyzed statistically using one way analysis of variance (ANOVA) followed by Tukey's test with $p<0.05$ $\left({ }^{*}\right)$ considered as statistically significant. All statistical analyses were performed with the software program SigmaStat (SigmaStat 3.1, 2004, Excel, 2007, USA).

\section{Results and discussion}

The modification of surfaces using plasma techniques are becoming increasingly common in biomaterials engineering. The most important advantage of plasma surface modifications is the 


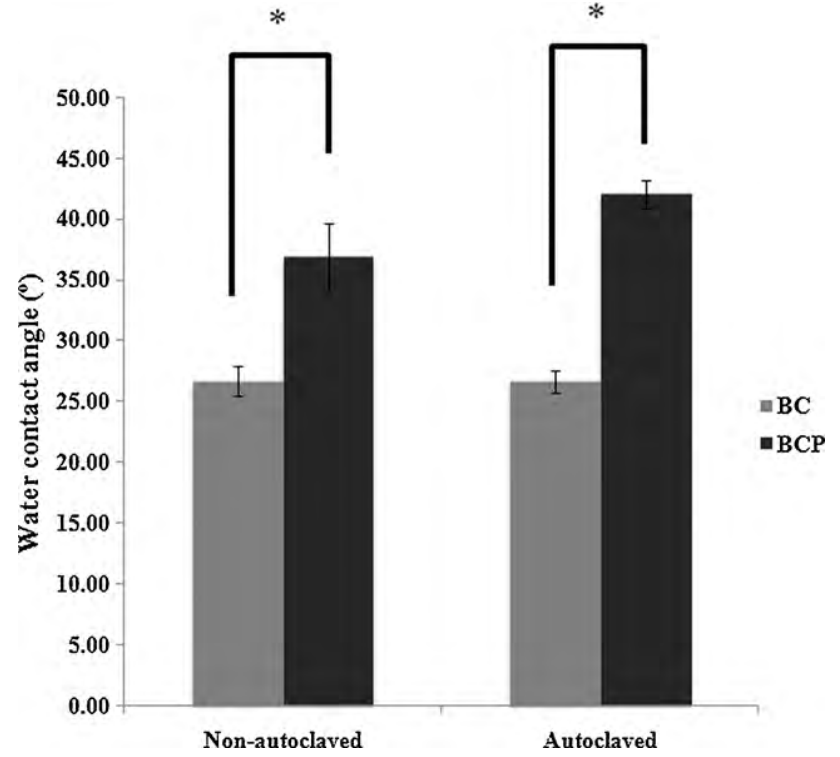

Fig. 1. Effect of nitrogen plasma treatment on the water contact angle on BC membranes. ${ }^{*} p<0.05$ considered as statistically significant.

ability to selectively change the surface properties, improving biocompatibility and mimicking the local tissue environment without altering the bulk attributes. Plasma thus provides a versatile and effective means to modify surfaces, enhancing the physicochemical properties and optimizing the biofunctionality (Chu et al., 2002). The nitrogen plasma is often used to modify metals, polymers and polymeric membranes, aiming the introduction of amino groups in the polymer surface and therefore, changing its polarity, reactivity and wettability (Charpentier, Maguire, \& Wan, 2006; Kull, Steen, \& Fisher, 2005).

The bacterial cellulose membranes were submitted to nitrogen plasma treatment with the purpose of enhancing the cell-material interactions. Wettability, evaluated through the measurement of the contact angle of a liquid on a surface, is a sensitive way to detect surface modifications (Charpentier et al., 2006). Furthermore, it is a measure of the hydrophilic/hydrofobic character of a material, a relevant property regarding biocompatibility, since it has a major influence on protein adsorption and interaction with cells. In this work, the wettability of the plasma-treated (BCP) and untreated bacterial cellulose (BC) was evaluated by water contact angle measurements. The results showed a slight increase in contact angles in the BCP membranes, the effect of sterilization - also analyzed in this study - being not significant. Overall, a slight reduction in the wettability (lower hydrophilicity) follows from the plasma treatment (Fig. 1). According to Deslandes et al. (1998), this behaviour is not directly related with the plasma treatment. In the work performed by this author, the contact angle of pure cellulose paper sheets increases (as in this work), in control experiments were the material is processed without ignition of the plasma; indeed, these samples were significantly more hydrophobic than the untreated cellulose. The reduction in hydrophilicity of the cellulose samples processed in the plasma chamber - without plasma - was assigned to the removal of physisorbed water and other volatile molecules,

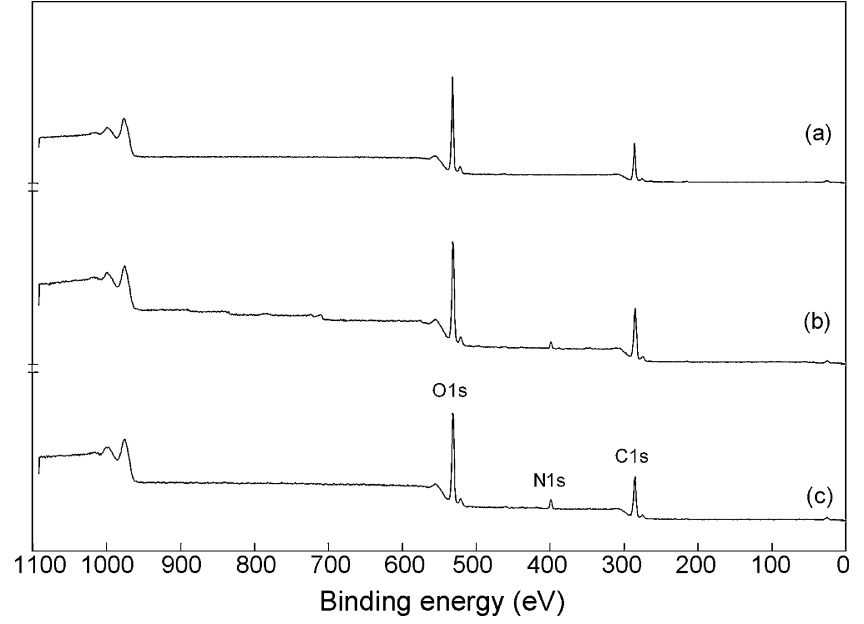

Fig. 2. XPS survey spectra of: (a) BC, (b) autoclaved BCP and (c) BCP.

which tend to render the surface hydrophilic (Deslandes et al. 1998).

The pressure applied in the plasma treatment may influence the final surface hydrophilicity of the material. Wang et al. (2006) studied the effect of oxygen and nitrogen plasma treatment on PHBV films. The authors observed that the contact angles decrease slightly with the exposure time, for both oxygen and nitrogen plasma treatments. However, when the pressure of the chamber increases, the contact angle decrease for the oxygen-plasma treatment and increase for the nitrogen plasma (Wang et al., 2006). The pressure used in our work ( 4 mbar) was higher than the ones used by Wang et al. (0.08-0.4 mbar). Another parameter with influence on the $\mathrm{BC}$ contact angle is the time of operation, $30 \mathrm{~min}$ in the current work. According to previous works (Bhat \& Upadhyay, 2002; Chan, Ko, \& Hiraoka, 1996) a short time (1-3 min) treatment in a nitrogen atmosphere result in more hydrophilic surfaces. In contrast, longer treatments (i.e. $>3 \mathrm{~min}$ ) decrease the surface hydrophilicity. Thus, the effect of plasma on the surface hydrophilicity is not straightforward; composition, pressure and time influence in a complex way the final effect. It is not in the scope of this study to analyse this complex function, which demonstrates the versatility of the technique.

In the modification of polymer materials with low-pressure plasmas, various components such as electrons, ions, radicals, as well as UV radiation are involved and interact with the exposed surfaces (Oehr, 2003). When high energetic particles of the plasma impact the material surface, chemical bonds are broken while new ones form, thus the chemical environment may change. XPS analysis was employed to analyse the modifications taking place during the plasma treatment. The relative atomic concentration of $\mathrm{O}, \mathrm{C}$ and $\mathrm{N}$ on the BC and BCP surface is shown in Table 1. An increase in the concentration of surface nitrogen was provided by plasma environment, as expected. Fig. 2 shows the XPS survey spectra, highlighting the $\mathrm{N} 1 \mathrm{~s}$ peak on $\mathrm{BCP}$. Sterilization at $121^{\circ} \mathrm{C}$ removes nitrogen to some extent; on the other hand, the surface composition of BCP is stable at room temperature. Indeed, after 180 days, the concentration of nitrogen, carbon and oxygen did not show any significant modification (Table 2).

Table 1

BC and BCP elemental composition analyzed by XPS.

\begin{tabular}{|c|c|c|c|c|c|c|}
\hline Surface modification & Autoclaved $(\mathrm{Y} / \mathrm{N})$ & Oxygen (\%) & Carbon (\%) & Nitrogen (\%) & $\mathrm{O} / \mathrm{C}$ & $\mathrm{N} / \mathrm{C}$ \\
\hline $\mathrm{BC}$ & $\mathrm{N}$ & 45.20 & 54.79 & 0.01 & 0.82 & 0.0001 \\
\hline \multirow[t]{2}{*}{$\mathrm{BCP}$} & $\mathrm{N}$ & 38.31 & 55.79 & 5.90 & 0.69 & 0.1057 \\
\hline & $\mathrm{Y}$ & 36.66 & 59.75 & 3.59 & 0.61 & 0.0600 \\
\hline
\end{tabular}


Table 2

$\mathrm{BCP}$ ageing.

\begin{tabular}{|c|c|c|c|c|c|}
\hline Surface modification & Days after treatment & Oxygen (\%) & Carbon (\%) & Nitrogen (\%) & $\mathrm{O} / \mathrm{C}$ \\
\hline \multirow{3}{*}{$\mathrm{BCP}$} & 15 & 38.31 & 55.79 & 5.90 & 0.68 \\
\hline & 50 & 38.88 & 55.83 & 5.29 & 0.69 \\
\hline & 180 & 37.81 & 56.52 & 5.67 & 0.66 \\
\hline
\end{tabular}

Additional insight into the surface chemistry can be obtained through deconvolution of the XPS spectra. The $\mathrm{C} 1 \mathrm{~s}, \mathrm{O} 1 \mathrm{~s}$ and $\mathrm{N} 1 \mathrm{~s}$ peaks of BC and BCP are shown in Fig. 3 and Table 3. The binding energy of $C$ ls and its spectra deconvolution are well documented. There is a general agreement on the assignment of components C1, C2, C3 and C4 of C 1s peak in wood-derived material (Dorris \& Gray, 1978a; Dorris \& Gray, 1978b; Gray, 1978; Hon, 1984; Mjoberg, 1981; Takeyama \& Gray, 1982). C1 corresponds to carbon only linked to hydrogen or carbon $(-\mathrm{C}-\mathrm{H},-\mathrm{C}-\mathrm{C})$; $\mathrm{C} 2$ is assigned to carbon linked to a single oxygen $(-\mathrm{C}-\mathrm{O})$, whereas $\mathrm{C} 3$ binds two non-carbonyl oxygen $\mathrm{O}-\mathrm{C}-\mathrm{O}$, or a single carbonyl oxygen $(-\mathrm{C}=0)$ and finally $\mathrm{C} 4$ represents carbon atoms linked to a carbonyl and a non-carbonyl oxygen $(\mathrm{O}-\mathrm{C}=\mathrm{O})$ (Hua, Kaliaguine, Kokta, \& Adnot, 1993).

Pure cellulose is a homopolysaccharide composed of $\beta$-Dglucopyranose units. Each monosaccharide unit contains five carbon atoms linked to one of oxygen and another carbon linked to two oxygen atoms. Thus, one expects a curve-resolved XPS C
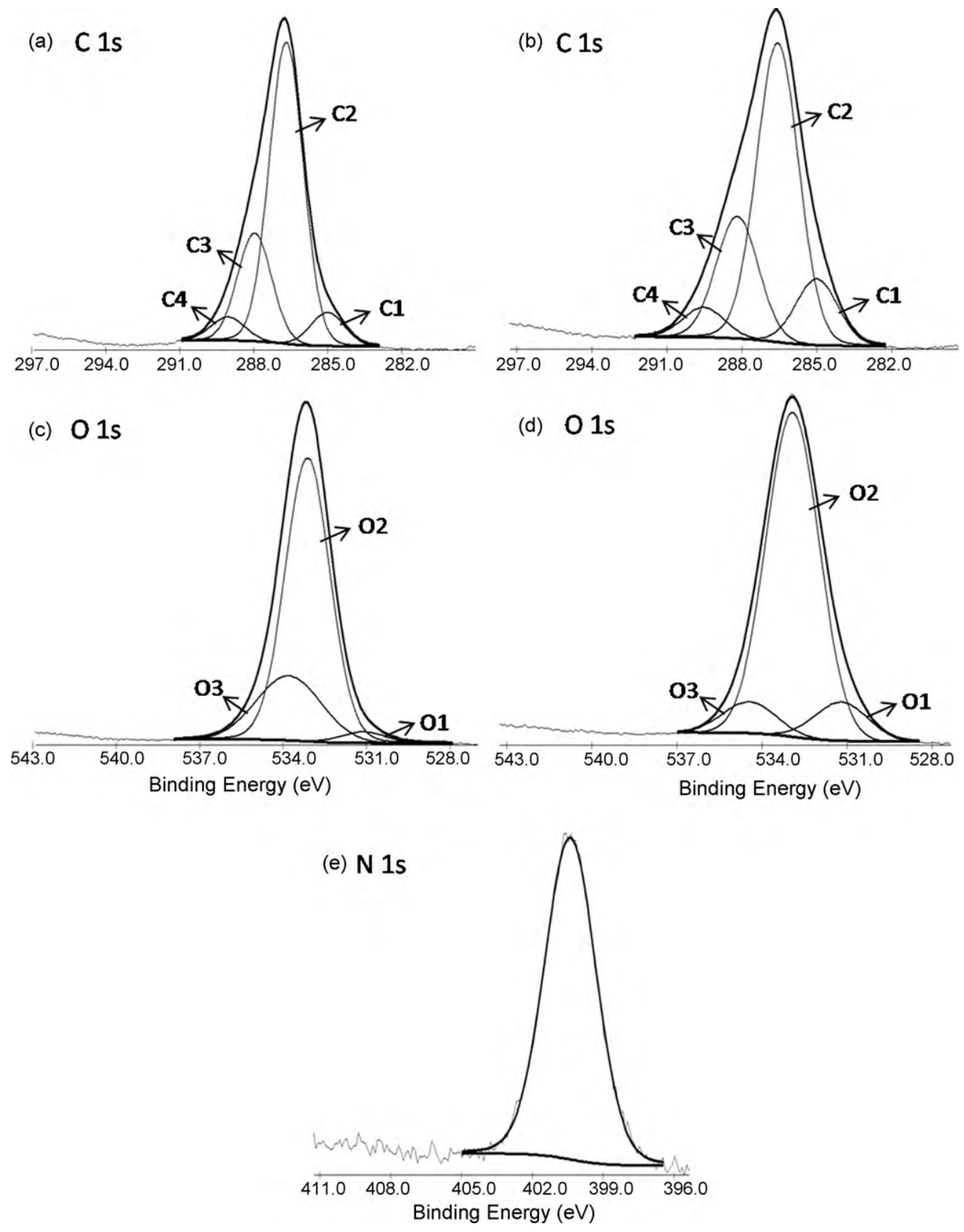

Fig. 3. Deconvolution of the carbon peak for: (a) BC, (b) BCP and oxygen peak for (c) BC, (d) BCP and (e) nitrogen peak for BCP. 
Table 3

Concentration of different functional groups on BC and BCP.

\begin{tabular}{|c|c|c|c|}
\hline Bacterial cellulose & Peaks (\%) & Binding energy (eV) & Assignment \\
\hline \multicolumn{4}{|l|}{ BC } \\
\hline C 1s (1) & 7.22 & 285.0 & Non-functionalised carbon (C-C; C-H) \\
\hline C $1 \mathrm{~s}(2)$ & 64.56 & 286.67 & Carbon linked to oxygen by a simple bound \\
\hline C $1 \mathrm{~s}(3)$ & 23.15 & 287.96 & $\begin{array}{l}\text { Carbon linked to two oxygen atoms by simple bounds }(\mathrm{O}-\mathrm{C}-\mathrm{O}) \text {; carbon linked to one oxygen } \\
\text { atom by double bound }(-\mathrm{C}=\mathrm{O}) \text {; amide }\left(\mathrm{CO}-\mathrm{NH}_{2}\right)\end{array}$ \\
\hline C $1 \mathrm{~s}(4)$ & 5.05 & 289.04 & Carbon in -COOR (carboxylic acids, esters, lactones, anhydrides) \\
\hline $01 \mathrm{~s}(1)$ & 2.96 & 531.12 & Amide groups $-\mathrm{CONH}_{2}$ \\
\hline $01 \mathrm{~s}(2)$ & 73.45 & 533.12 & $-\mathrm{OH}$ groups of cellulose \\
\hline $01 \mathrm{~s}(3)$ & 23.58 & 533.79 & $-\mathrm{COOH}$ \\
\hline \multicolumn{4}{|l|}{ BCP } \\
\hline C 1s (1) & 12.79 & 285.0 & Non-functionalised carbon (C-C; C-H) \\
\hline C 1s (2) & 57.75 & 286.56 & Carbon linked to oxygen by a simple bound and carbon linked to nitrogen in nitrile (C-N) \\
\hline C 1s (3) & 23.66 & 288.17 & $\begin{array}{l}\text { Carbon linked to two oxygen atoms by simple bounds }(\mathrm{O}-\mathrm{C}-\mathrm{O}) \text {; carbon linked to one oxygen } \\
\text { atom by double bound }(-\mathrm{C}=\mathrm{O}) \text {; amide }\left(\mathrm{CO}-\mathrm{NH}_{2}\right)\end{array}$ \\
\hline C $1 \mathrm{~s}(4)$ & 5.78 & 289.52 & Carbon in -COOR (carboxylic acids, esters, lactones, anhydrides) \\
\hline $01 \mathrm{~s}(1)$ & 9.82 & 531.21 & Amide groups $-\mathrm{CONH}_{2}$ \\
\hline $01 \mathrm{~s}(2)$ & 82.17 & 532.93 & $-\mathrm{OH}$ groups of cellulose \\
\hline $01 \mathrm{~s}(3)$ & 8.01 & 534.46 & $-\mathrm{COOH}$ \\
\hline
\end{tabular}

1s signal to consist of only two peaks (C2 and C3). The carbon composition, $\mathrm{C} 1 / \mathrm{C} 2 / \mathrm{C} 3 / \mathrm{C} 4$ for the pure cellulose is expected to be [0:83:17:0] (Carlsson \& Strom, 1991). However, the carbon composition determined using filter paper, as given by XPS measurements in a work developed by Carlsson and Strom (1991), was found to be [8:72:17:3]. According to these authors, the appearance of the two peaks C1 and C4 may be due to either a contamination of the filter paper and/or to a chemical change in the cellulose structure. Likewise, the XPS characterization of bacterial cellulose, by Li, Wan, Li, Liang, and Wang (2009), showed that the C (1s) spectra presented three peaks, at $285 \mathrm{eV}(\mathrm{C}-\mathrm{C}), 286.6(\mathrm{C}-\mathrm{O}, \mathrm{C}-\mathrm{OH})$ and $288.3 \mathrm{eV}$ $(\mathrm{O}-\mathrm{C}-\mathrm{O}, \mathrm{C}=\mathrm{O})$. In the present work, $\mathrm{BC}$ presented four carbon peaks corresponding to $\mathrm{C} 1, \mathrm{C} 2, \mathrm{C} 3$ and $\mathrm{C} 4$. The $\mathrm{C} 1(\mathrm{C}-\mathrm{C})$ peak should be representative of ubiquitous contamination of cellulose by carbon and oxygen in air-exposed surfaces (Johansson \& Campbell, 2004). The $C 4$ peak could be attributed to $C 1$ core level of carbon atoms in carboxyl groups $(\mathrm{O}-\mathrm{C}=\mathrm{O})$ (Belgacem, Czeremuszkin, Sapieha, \& Gandini, 1995; Sapieha, Verreault, Klemberg-Sapieha, Sachet, \& Wertheimer, 1990).

The $\mathrm{O} 1 \mathrm{~s}$ peak in the $\mathrm{BC}$ and $\mathrm{BCP}$ samples corresponds mainly to two forms of oxygen: $\mathrm{O} 2$ oxygen in $\mathrm{OH}$ groups of cellulose, $\mathrm{O} 3$ oxygen in $\mathrm{C}-\mathrm{O}-\mathrm{C}$ and $\mathrm{O}-\mathrm{C}-\mathrm{O}$ groups; the $\mathrm{O} 1$ is the most intense component peak, representing 73.45 and $82.17 \%$ of the $O 1$ s total areas in the untreated and treated celluloses, respectively. The 01 peak is related to amide groups $-\mathrm{CONH}_{2}$ (Cagniant et al., 2002).

Nitrogen plasma induces the incorporation of various chemical functionalities onto the polymer surface. On exposure to this kind of treatment, the incorporation of $\mathrm{N}$-containing functional groups - such as amine, imine, amide, nitrile - on different materials has been described, whose distribution and density can be tuned with the plasma parameters, and depend also on ageing processes (Gancarz, Pozniak, \& Bryjak, 2000; Salerno et al., 2009). Through nitrogen plasma treatment $\mathrm{N}$-groups were incorporated at the $\mathrm{BC}$ surface. The component $\mathrm{N} 1 \mathrm{~s}$ was decomposed in only one peak at a binding energy of $400.39 \mathrm{eV}$. According to the literature (Cagniant et al., 2002; Jansen \& van Bekkum, 1994), this binding energy $(400.2 \pm 0.10 \mathrm{eV})$ is assigned to amides, lactams and nitriles.

The $\mathrm{O} / \mathrm{C}$ atomic ratio of $\mathrm{BC}$ was found to be 0.82 (Table 1 ), a value in agreement with the theoretical one in pure cellulose $(0.83)$ (Topalovic et al., 2007). After the plasma treatment, the $\mathrm{O} / \mathrm{C}$ atomic ratio changed to 0.69 and 0.61 , for the non-sterilized and sterilized $\mathrm{BCP}$, respectively. These values are close to those -0.55 and $0.62-$ reported by Topalovic et al. (2007) and Li et al. (2009).

Changes in hydrophilicity induced by the implantation of polar functional groups can be time-dependent, an effect often called "ageing", reported by many researchers on modified polymer surfaces. The nitrogen plasma modification of BCP membranes was examined along time by XPS, in order to access the stability of the nitrogen groups incorporated on the surface. Chain migration in the surface region can result in gradual deterioration of the surface properties. Our results showed that the functional groups present on BCP surface are stable at room temperature, up to 180 days. The long-term stability of a modified polymer surface is important whenever the material is not stored in a controlled environment or coated immediately after treatment. Several factors have been reported to influence the stability of modified surfaces, including contamination, the chemical structure of the original polymer, electrical properties, the degree of plasma modification (operational conditions), the plasma gas, the storage environment, all may contribute to the overall decay phenomenon (Bhat \& Upadhyay, 2002; Gerenser, 1993).

In the work developed by Bhat and Upadhyay (2002), the effect of storage time on the surface energy of unoriented polypropylene films (UPP) treated with nitrogen plasma was analyzed over a period of 2 months. UPP films treated in nitrogen plasma for 3 min showed a gradual reduction of the surface energy along with the storage time, whereas films treated for $10 \mathrm{~min}$ were stable According to the authors, the re-orientation of mobile groups is responsible for the observed change in surface energy. For the shorter treatment time, hydrophilic groups are incorporated on the polymer surface, and as a result, surface energy is improved only for freshly treated samples. However, for the samples stored for 2 months, hydrophilic groups reorients toward each other and also toward the interior. Because of this, hydrophilic groups do not face the air-liquid interface and therefore the contact angle increases and surface energy decreases. For a longer treatment time (10 min), the crosslinking reactions avoid the mobile group to reorient easily, such that the surface energy remains constant (Bhat \& Upadhyay, 2002). In the current case, since $B C$ was treated for 30 min with nitrogen plasma, a crosslinked surface, leading to a permanent binding of $\mathrm{N}$ atom to the polymer chain, may thus be responsible for the observed stability.

Sterilizability is a mandatory requirement for biomedical materials, which must contact cells or tissues. Among the various methods of sterilization, the most frequently applied is hot vapor sterilization $\left(121^{\circ} \mathrm{C}, 21 \mathrm{~min}\right)$. This method is preferred as long as the materials are stable (Oehr, 2003). Once bacterial cellulose is a thermally stable material, we evaluated whether the functional groups formed by plasma treatment remains stable after autoclaving. Our results showed a decrease in $\mathrm{N}_{2}$ content (5.90-3.59\%) after 

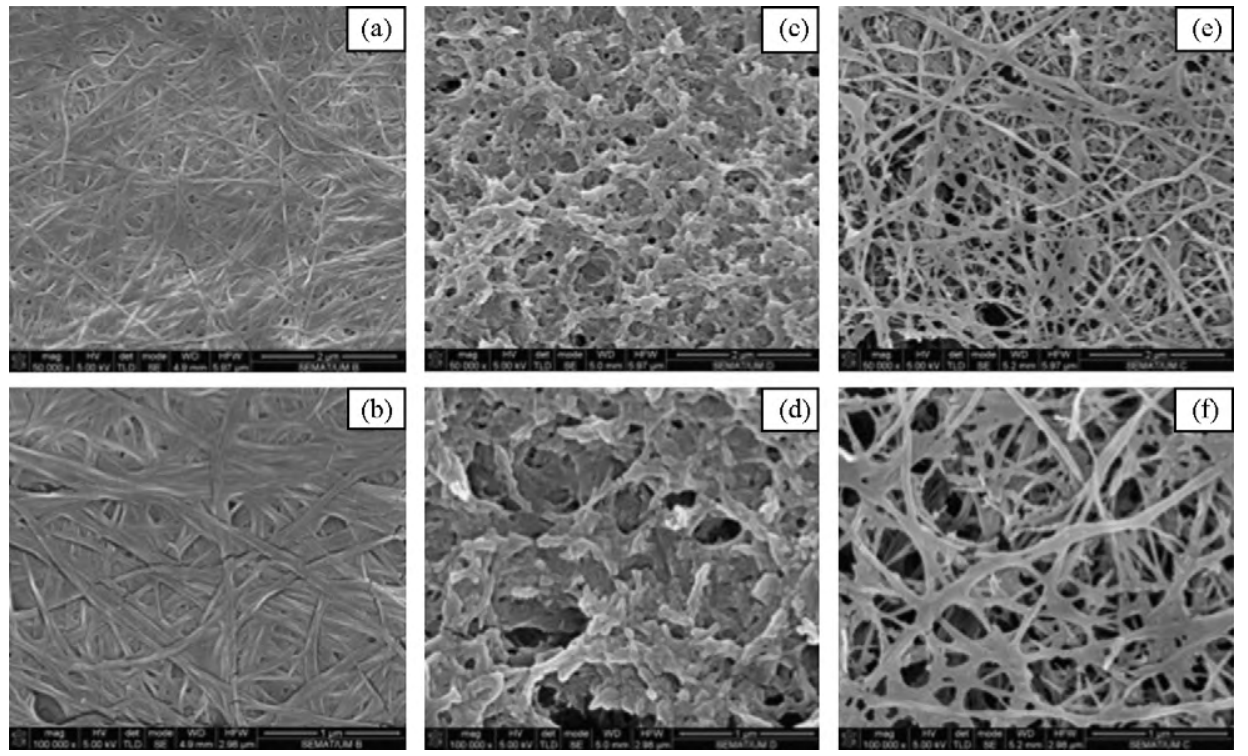

Fig. 4. SEM micrographs of bacterial cellulose. $B C$ ( $a$ and b), BCP ( $c$ and d) and autoclaved $B C P$ (e and f).

the process. However, even with the decrease of nitrogen after the sterilization, the functional groups present on the surface were able to enhance the cell affinity for BC.

It has been demonstrated, using several materials (Lucchesi et al., 2008; Vidaurre, Achete, Simao, \& Habert, 2001; Yang et al., 2002), that plasma may increase the surface roughness. The SEM observations reveal that plasma produces morphological changes on BC. Fig. 4 shows SEM images of BC and BCP, autoclaved and non-autoclaved. While $\mathrm{BC}$ presents relatively low porosity and a tight inter-fiber contact, the plasma treatment seems to disrupt the fibers to some extent, leading to a more porous and rough material. These changes in the surface topography are mostly caused by chemical erosion and physical erosion by atoms and ions in the plasma (Vesel et al., 2008). However, unlike reported by Yang et al. (2002), the increased roughness does not lead in this case to the enhancement of the hydrophilicity of the plasma-treated samples, as discussed previously. Furthermore, the SEM images show the typical micro-channels pattern of $\mathrm{BC}$, which maintained the 3D network structure after plasma treatment. Apparently, autoclaving increases even more the porosity of the scaffold (Fig. 4). The plasma treatment and autoclaving resulted in $\mathrm{BC}$ membranes with larger inter-fiber porosity, which is likely to favour the permeability of nutrients and cell communication and thus representing a promising method for the development of BC scaffolds for tissue engineering. Actually, the change in roughness and porosity has been shown to play a significant effect on the protein and cell attachment, while oxygen as well as nitrogen-containing plasma has been shown to increase endothelia cell attachment (Vesel et al., 2008).

Biocompatibility is not an inherent property of a material, but results from complex interactions between an implant and the surrounding tissues. Any polymer used in biomedical application should be biocompatible, which requires, among other properties, a low friction coefficient, appropriate surface topography, chemistry and hydrophilicity (Gomathi, Sureshkumar, \& Neogi, 2008; Wei et al., 2007). It is known that BC is a very hydrophilic polymer; however, cell-material interactions are not only influenced by a defined balance of hydrophilicity/hydrophobicity, but also by the presence of special functional groups (Klee, Villari, Hocker, Dekker, \& Mittermayer, 1994). In tissue engineering, cell adsorption is critical, because adhesion occurs before other events like cell spreading, migration and differentiation (Wan, Yang, Yang, Bei, \&

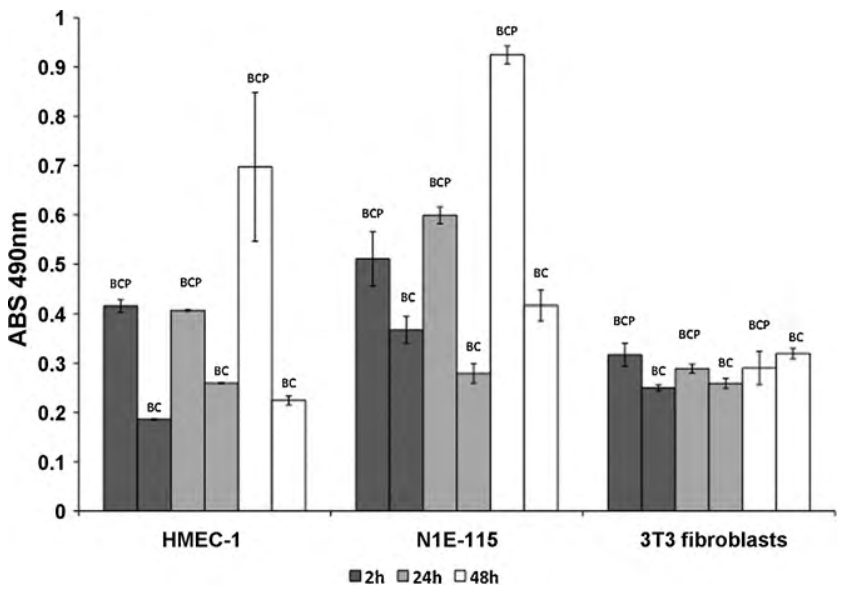

Fig. 5. MTS assays of HMEC-1, N1E-115 and $3 \mathrm{~T} 3$ fibroblast cultured on BC and BCP. The MTS assay was developed at 2, 24 and $48 \mathrm{~h}$ after cells addition. Results are expressed in terms of absorbance.

Wang, 2003). In this context, BC may be improved as to induce a better cell adhesion and even better biocompatibility. The nitrogen plasma treatment was chosen and proved to effectively enhance cell affinity through functional nitrogen groups grafted on the surface material. The MTS results (Fig. 5) showed that the modification by nitrogen plasma efficiently improve the adhesion of N1E-115 and HMEC- 1 cells, by 2 -fold in the case of HMEC and by $25 \%$ in the case of neuroblasts (according to the viable cells detected $2 \mathrm{~h}$ after cell seeding). Not only the cells adhere in higher number, proliferation is also more exuberant on BCP. However, in the case of the 3T3 fibroblasts, the treatment showed no effect in the timeframe analyzed (2-48 h). Thus, different cell display a different behaviour in contact with modified biopolymers.

\section{Conclusions}

Plasma surface modification is an effective and economical surface treatment technique, drawing great interest in biomedical engineering. The nitrogen plasma treatment used in this work was able to increase the concentration of functional groups on BC surface in a very stable way along time and also capable to improve the 
adhesion of endothelial and neuroblast cells to the material. Therefore, the surface modification leads to a better cell affinity with BC, probably contributing for a better biocompatibility in vivo. It must be remarked that the plasma treatment improves significantly the porosity of the material. This is a very important result, since the relatively low porosity of $\mathrm{BC}$ is a main drawback in the development of tissue engineering applications, because it is the reason for the poor cell penetration. Thus, forthcoming work will address the characterization of the mechanical properties of the treated $\mathrm{BC}$ as well as the analysis of the cell migration through the material, and viability of the cells inside the plasma-treated BC.

\section{Acknowledgements}

The author R.A.N. Pértile gratefully acknowledges support by the Programme Alßan, the European Union Programme of High Level Scholarships for Latin America (Scholarship No. E07D401931BR). F.K. Andrade is the recipient of a fellowship from Coordenação de Aperfeiçoamento de Pessoal de Nível Superior (CAPES, Brazil). The authors wish to acknowledge the FCT/POCTI Portugal and Conselho Nacional de Desenvolvimento Científico e Tecnológico Brazil (CNPq). The authors thank Prof Carlos Sá, from CEMUP, Oporto, for the support on the analysis of XPS data.

\section{References}

Belgacem, M. N., Czeremuszkin, G., Sapieha, S., \& Gandini, A. (1995). Surface characterization of cellulose fibres by XPS and inverse gas chromatography. Cellulose, 2, 145-157.

Bhat, N. V., \& Upadhyay, D. J. (2002). Plasma-induced surface modification and adhesion enhancement of polypropylene surface. Journal of Applied Polymer Science, 86(4), 925-936.

Cagniant, D., Magri, P., Gruber, R., Berlozecki, S., Salbut, P. D., Bimer, J., et al. (2002). Ammoxidation of cellulose-A structural study. Journal of Analytical and Applied Pyrolysis, 65, 1-23.

Carlsson, C. M. G., \& Strom, G. (1991). Reduction and oxidation of cellulose surfaces by means of cold-plasma. Langmuir, 7(11), 2492-2497.

Chan, C. M., Ko, T. M., \& Hiraoka, H. (1996). Polymer surface modification by plasmas and photons. Surface Science Reports, 24(1-2), 3-54.

Charpentier, P. A., Maguire, A., \& Wan, W. K. (2006). Surface modification of polyester to produce a bacterial cellulose-based vascular prosthetic device. Applied Surface Science, 252(18), 6360-6367.

Chu, P. K., Chen, J. Y., Wang, L. P., \& Huang, N. (2002). Plasma-surface modification of biomaterials. Materials Science and Engineering R-Reports, 36(5-6), 143-206.

Costa, T. H. C., Feitor, M. C., Alves, C., Freire, P. B., \& de Bezerra, C. M. (2006). Effects of gas composition during plasma modification of polyester fabrics. Journal of Materials Processing Technology, 173(1), 40-43

Deslandes, Y., Pleizier, G., Poiré, E., Sapieha, S., Wertheimer, M. R., \& Sacher, E. (1998) The surface modification of pure cellulose paper induced by low-pressure nitrogen plasma treatment. Plasma and Polymers, 3(2), 61-76.

Dorris, G. M., \& Gray, D. G. (1978a). The surface analysis of paper and wood fibers by ESCA I. Cellulose Chemistry and Technology, 12, 9-23.

Dorris, G. M., \& Gray, D. G. (1978b). The surface analysis of paper and wood fibers by ESCA II. Cellulose Chemistry and Technology, 12, 721-734.

Gancarz, I., Pozniak, G., \& Bryjak, M. (2000). Modification of polysulfone membranes 3. Effect of nitrogen plasma. European Polymer Journal, 36(8), 1563-1569.

Gerenser, L. J. (1993). Xps studies of in-situ plasma-modified polymer surfaces. Journal of Adhesion Science and Technology, 7(10), 1019-1040.

Gomathi, N., Sureshkumar, A., \& Neogi, S. (2008). RF plasma-treated polymers for biomedical applications. Current Science, 94(11), 1478-1486.

Gray, D. G. (1978). The surface analysis of paper and wood fibers by ESCA III. Cellulose Chemistry and Technology, 12, 735-743.

Helenius, G., Backdahl, H., Bodin, A., Nannmark, U., Gatenholm, P., \& Risberg, B. (2006). In vivo biocompatibility of bacterial cellulose. Journal of Biomedical Materials Research Part A, 76A(2), 431-438.
Hon, D. N. S. (1984). ESCA study of oxidized wood surfaces. Journal of Applied Polymer Science, 29, 2777-2784

Hua, X., Kaliaguine, S., Kokta, B. V., \& Adnot, A. (1993). Surface-analysis of explosion pulps by Esca. 1. Carbon (1s) spectra and oxygen-to-carbon ratios. Wood Science and Technology, 27(6), 449-459.

Jansen, R. J. J., \& van Bekkum, H. (1994). Amination and ammoxidation of activated carbons. Carbon, 32, 1507-1516.

Johansson, L.-S., \& Campbell, J. M. (2004). Reproducible XPS on biopolymers: Cellulose studies. Surface and Interface Analysis, 36, 1018-1022.

Klee, D., Villari, R. V., Hocker, H., Dekker, B., \& Mittermayer, C. (1994). Surface modification of a new flexible polymer with improved cell-adhesion. Journal of Materials Science: Materials in Medicine, 5(9-10), 592-595.

Kull, K. R., Steen, M. L., \& Fisher, E. R. (2005). Surface modification with nitrogencontaining plasmas to produce hydrophilic, low-fouling membranes. Journal of Membrane Science, 246(2), 203-215.

Kwok, D. Y., \& Neumann, A. W. (1999). Contact angle measurement and contact angle interpretation. Advances in Colloid and Interface Science, 81(3), 167-249.

Li, J., Wan, Y. Z., Li, L. F. Liang, H., \& Wang, J. H. (2009). Preparation and characterization of 2,3-dialdehyde bacterial cellulose for potential biodegradable tissue engineering scaffolds. Materials Science and Engineering C: Biomimetic and Supramolecular Systems, 29(5), 1635-1642.

Lucchesi, C., Ferreira, B. M. P., Duek, E. A. R., Santos, A. R., \& Joazeiro, P. P. (2008). Increased response of Vero cells to PHBV matrices treated by plasma. Journal of Materials Science: Materials in Medicine, 19(2), 635-643.

Ma, Z., Mao, Z., \& Gao, C. (2007). Surface modification and property analysis of biomedical polymers used for tissue engineering. Colloids Surface B: Biointerfaces, 60(2), 137-157.

Mjoberg, P. J. (1981). Chemical surface analysis of wood fibers by means of ESCA Cellulose Chemistry and Technology, 15, 481-486.

Oehr, C. (2003). Plasma surface modification of polymers for biomedical use. Nuclear Instruments and Methods in Physics Research Section B: Beam Interactions with Materials and Atoms, 208, 40-47.

Salerno, S., Piscioneri, A., Laera, S., Morelli, S., Favia, P., Bader, A., et al. (2009) Improved functions of human hepatocytes on $\mathrm{NH}_{3}$ plasma-grafted PEEK-WC-PU membranes. Biomaterials, 30(26), 4348-4356.

Sapieha, S., Verreault, M., Klemberg-Sapieha, J. E., Sachet, E., \& Wertheimer, M. R. (1990). X-Ray photoelectron study of the plasma fluorination of lignocellulose. Applied Surface Science, 44, 165-169.

Svensson, A., Harrah, T., Panilaitis, B., Kaplan, D., \& Gatenholm, P. (2004). Bacterial cellulose as a substrate for tissue engineering of cartilage. Abstracts of Papers of the American Chemical Society, 227, U282-U1282.

Takeyama, S., \& Gray, D. G. (1982). An ESCA study of the chemisorption of stearic acid vapor on cellulose. Cellulose Chemistry and Technology, 16, 133-142.

Topalovic, T., Nierstrasz, V. A., Bautista, L., Jocic, D., Navarro, A., \& Warmoeskerken, M. M. C. G. (2007). XPS and contact angle study of cotton surface oxidation by catalytic bleaching. Colloids and Surfaces A: Physicochemical and Engineering Aspects, 296(1-3), 76-85.

Vandamme, E. J., De Baets, S., Vanbaelen, A., Joris, K., \& De Wulf, P. (1998). Improved production of bacterial cellulose and its application potential. Polymer Degradation and Stability, 59(1-3), 93-99.

Vesel, A., Junkar, I., Cvelbar, U., Kovac, J., \& Mozetic, M. (2008). Surface modification of polyester by oxygen- and nitrogen-plasma treatment. Surface and Interface Analysis, 40(11), 1444-1453.

Vidaurre, E. F. C., Achete, C. A., Simao, R. A., \& Habert, A. C. (2001). Surface modification of porous polymeric membranes by RF-plasma treatment. Nuclear nstruments and Methods in Physics Research Section B: Beam Interactions with Materials and Atoms, 175, 732-736.

Wan, Y. Q., Yang, J., Yang, J. L., Bei, J. Z., \& Wang, S. G. (2003). Cell adhesion on gaseous plasma modified poly-(L-lactide) surface under shear stress field. Biomaterials, $24(21), 3757-3764$

Wang, Y., Lu, L., Zheng, Y., \& Chen, X. (2006). Improvement in hydrophilicity of PHBV films by plasma treatment. Journal of Biomedical Materials Research Part A, 76(3) 589-595.

Wang, Y. X., Robertson, J. L., Spillman, W. B., Jr., \& Claus, R. O. (2004). Effects of the chemical structure and the surface properties of polymeric biomaterials on their biocompatibility. Pharmaceutical Research, 21(8), 1362-1373.

Wei, J. H., Yoshinari, M., Takemoto, S., Hattori, M., Kawada, E., Liu, B. L, et al. (2007). Adhesion of mouse fibroblasts on hexamethyidisiloxane surfaces with wide range of wettability. Journal of Biomedical Materials Research Part B: Applied Biomaterials, 81B(1), 66-75.

Yang, J., Bei, J. Z., \& Wang, S. G. (2002). Enhanced cell affinity of poly (D,L-lactide) by combining plasma treatment with collagen anchorage. Biomaterials, 23(12) 2607-2614. 